\title{
Twelve years of global survival in squamous head and neck carcinoma. What have we advanced in these years?
}

\author{
Maria del Carmen P González*, David G Abad, Beatriz A Pascual, Beatriz L Vila, Nadia S Baños, Ana MM Fernández and Juan A Guerra \\ Oncology Department, Universitary Hospital Fuenlabrada, Madrid, Spain
}

\section{Introduction}

Squamous cell carcinomas of the head and neck represent $7 \%$ of all malignant tumors. The overall 5-year survival for advanced-metastatic stages is $40-60 \%$ with a different prognosis whether it is associated with human papilloma virus (HPV) or not [1]. In these patients, overall survival has clearly increased in the last 10 years due to new treatments.

\section{Case report}

A 41-years-old smoker woman without any more medical illnesses to be highlighted. She went to the emergency room in June 2010 due to a bleeding injury in the back of her tongue that lasted three weeks. The lesion of the tongue was biopsied with pathological anatomy (PA) of squamous cell carcinoma identifying bilateral cervical lymph node metastases. Stage cT4N2M0.

DCF induction chemotherapy (docetaxel, cisplatin, $5 \mathrm{FU}) \times$ 3 cycles began in July 2010, followed by cisplatin chemotherapyradiotherapy (QTRT) with good tolerance. In the reevaluation CT, a response of the primary tumor was observed but with persistence of cervical lymphadenopathy, so, a bilateral functional cervical emptying was performed without signs of histological malignancy. She continued reviews with no evidence of illness.

Four years later, in the right edge epiglottis appeared one lesion with positive histology for squamous cell carcinoma and without disease at other levels on CT. Supraglottic larynguectomy and tracheostomy were decided in October 2014 with negative edges. Stage pT2 L0V0 R0.

In July 2015, there was evidence of a left paratracheal and a right paraesophageal mass that condition the airway obstruction, requiring a palliative tracheostomy (Figure 1). Unresectable recurrence was confirmed and treatment with weekly paclitaxel-cetuximab (ERBITAX) began with an almost complete early response (Figure 2) after 4 cycles that was maintained. Chemotherapy rest is decided by persistent radiological complete response.

In May 2017 (22 months without chemotherapy treatment) she began with dysphagia, performing an endoscopy which demonstrated an esophageal stenosis and pathological anatomy of squamous cell carcinoma. No evidence of disease at other levels. Weekly carboplatinpaclitaxel treatment was administered with partial response after six treatment cycles and excellent tolerance.

In February 2018, growth of the cervical esophageal lesion was observed, reintroducing paclitaxel cetuximab with lymph node progression after two cycles. It was decided to start the 3rd line with 5FU, folinic, oxaliplatin (FOLFOX) with partial tumor response.
In July 2018, recurrence on the right margin of the glossopharyngeal junction and lingual base with histology of squamous cell carcinoma. PD-L1 was determinated with positive result. After this, it was decided to start treatment with nivolumab with a decrease in esophageal thickening and paratracheal and subcarinal lymphadenopathy on february 2020 (Figure 3).

\section{Discussion}

Head and neck cancer are one of the neoplasms with the highest mutational burden, mainly in relation to mutations induced by tobacco, alcohol, and HPV [2]. Oropharyngeal tumors are associated with HPV

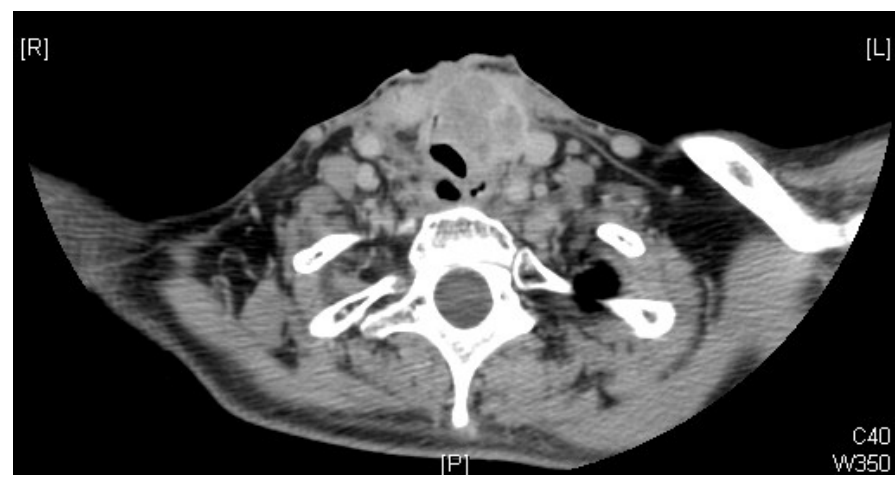

Figure 1. Left paratracheal mass that condition airway obstruction

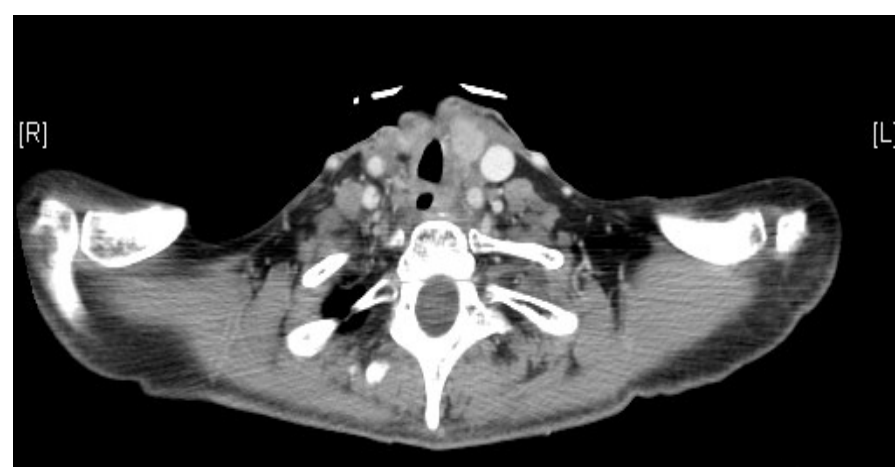

Figure 2. Decrease in tumor mass after ERBITAX

*Correspondence to: Maria del Carmen Pantín González, Oncology Department, Universitary Hospital Fuenlabrada, Madrid, Spain, Tel: +34 601168112; E-mail: carmenpantin1991@gmail.com

Received: June 05, 2020; Accepted: June 22, 2020; Published: June 25, 2020 


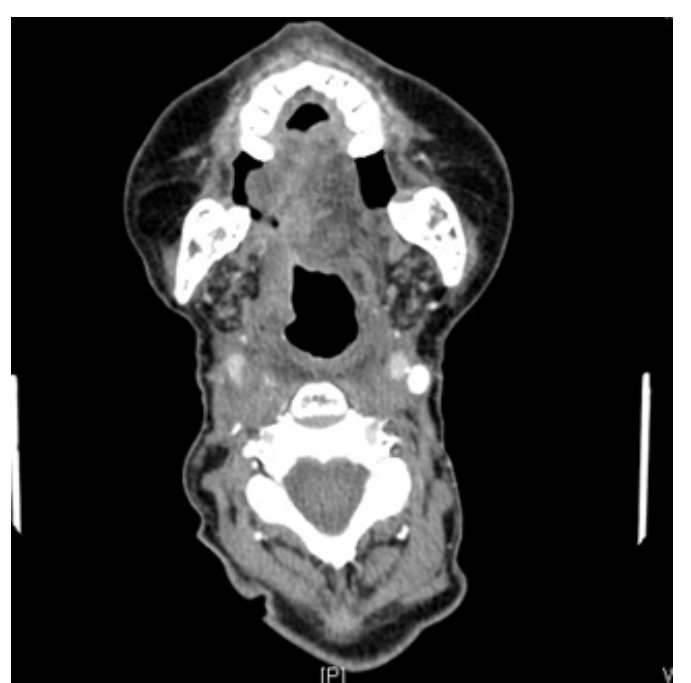

Figure 3. Decrease in paratracheal and subcarinal lymphadenopathy after starting nivolumab

in $16-25 \%$. Patients with positive HPV have a better prognosis due to a lower presence in these tumors of mutations in p53 gene (tumor suppressor gene) [3].

There is a correlation between PD-L1 and PD-L2 expression and response to treatment with immune checkpoint. PD-L1 overexpression in tumor cells transmits inhibitory signals causing a decrease in the activation of T lymphocytes, Natural Killer and B lymphocytes. It has long been known that inhibiting this pathway with antiPD1/antiPDL1 restores the innate anti-tumor activity of cytotoxic TCD8 cells [4].
In the CheckMate 141 study, it was observed that the HPV positive patients had an overall two-year survival of 9.1 months compared to 7.7 months in the negative ones, although both groups benefited from nivolumab significantly compared to those who did not [5]. Surgery in this case is of crucial importance since the free resection margins determine the prognosis in head and neck cancers.

\section{Conclusion}

In summary, this case report presents the natural history of squamous cell carcinoma of the head and neck with unusual behavior due to long survival, which conditions the appearance of different new malignancies associated with the carcinogenesis of these tumors.

Emphasize the importance of a multidisciplinary committee in these tumors since surgery, chemotherapy and immunotherapy are necessary for the correct management of these patients.

\section{Reference}

1. Siegel RL, Miller KD, Jennal A (2017) Cancer statistics, 2017. CA Cancer J Clin 67: 7-30. [Crossref]

2. Alexandrov LB, Nik-zainal S, Wedge DC, Aparicio SAJR (2014) Europe PMC Funders Group. Signatures of mutational processes in human cancer. Nature 500: 415-421.

3. Hanna GJ, Liu H, Jones RE, Bacay AF, Lizotte PH, et al. (2017) Defining an inflamed tumor immunophenotype in recurrent, metastatic squamous cell carcinoma of the head and neck. Oral Oncol 67: 61-69. [Crossref]

4. Yearley JH, Gibson C, Yu N, Moon C, Murphy E, et al. (2017) PD-L2 expression in human tumors: relevance to anti-PD-1 therapy in cancer. Clin Cancer Res 23: 31583167. [Crossref]

5. Ferris RL, Blumenschein G, Fayette J, Guigay J, Colevas AD, et al. (2016) Nivolumab for Recurrent Squamous-Cell Carcinoma of the Head and Neck. N Engl J Med 375: 1856-1867. [Crossref]

Copyright: (C2020 Maria del Carmen PG. This is an open-access article distributed under the terms of the Creative Commons Attribution License, which permits unrestricted use, distribution, and reproduction in any medium, provided the original author and source are credited. 